\title{
INCONTINÊNCIA DO CHORO E INFARTO PROTUBERANCIAL UNILATERAL
}

\author{
RICARDO DE OLIVEIRA - SOUZA*, WAGNER MARTIGNONI DE FIGUEIREDO**, \\ PEDRO ANGELO ANDREIUOLO***
}

\begin{abstract}
RESUMO - O presente estudo trata do caso de um paciente que apresentou incontinência do choro e hemiplegia direita por infarto ventroprotuberancial paramediano detectado pela RNM. O caráter circunscrito da lesão foi endossado pela normalidade dos potenciais evocados sômato-sensitivos e auditivos de curta-latência. Os episódios de choro desapareceram poucos dias depois do início do tratamento com doses baixas de imipramina. Discutimos o choro e riso patológicos como forma de incontinência da mímica resultante de desconexão límbico-motora, enfatizando a impropriedade de incluí-los na síndrome pseudobulbar, uma vez que dependem de correlatos anatômicos e funcionais distintos.
\end{abstract}

PALAVRAS-CHAVE: síndrome pseudobulbar, choro e riso patológico, hemiplegia motora pura, imipramina.

\section{Incontinence of crying and unilateral pontine infarct}

SUMMARY - A 64-year-old man presented with pathologic crying and right hemiplegia due to a unilateral pontine infarct from probable branch disease of the basilar artery. The circumscribed nature of the lesion was supported by MRI and short-latency evoked potentials. The weeping spells ceased after a few days of imipramine in low doses. Pathologic laughing and crying can be viewed as a limbic-motor disconnection syndrome, in which the faciovocal motor system is released from forebrain afferents carrying information of emotional content. The inclusion of pathologic laughing and crying in the syndrome pseudobulbar palsy is inaccurate and misleading, since each is related to distinct functional and anatomic systems intrinsic to the human brainstem.

KEY WORDS: pseudobulbar paralysis, pathologic laughing and crying, pure motor hemiplegia, imipramine.

Explosões de choro e riso em indivíduos privados da expressão das emoções delicadas e incapazes de articular palavra $\mathrm{c}$ mover a fisionomia sob comando, sempre fascinou estudiosos e leigos. Acrescente-se à estranheza da manifestação o depoimento de que não experimentam tristeza ou alegria nessas ocasiões. Essa constelação de sintomas foi reconhecida no final do século passado por Bechterew" e Brissaud ${ }^{12}$, que a denominaram, respectivamente, "choro incontido" ("unaufhaltsames Weinen") e "choro espasmódico" ("pleureur spasmodique"). A imobilidade da face a comandos voluntários, por um lado, e sua ampla movimentação nos acessos de choro, por outro, levou-os ao postulado da dupla inervação supranuclear da face humana: uma, "voluntária", identificada com lesão do contingente córtico-facial do feixe córtico-nuclear; outra, "emocional", cujos correlatos anatômicos exatos permanecem obscuros.

* Neurologista, Professor Assistente, Serviço de Clínica Médica C (Prof. Omar da Rosa Santos), Hospital Universitário Gaffrée e Guinle, UNI-RIO (HUGG-UNI-RIO); ** Clínico Geral, Professor Adjunto, Clínica Médica C(Prof. Omar da Rosa Santos), HUGG-UNI RIO; *** Radiologista, Hospital da Beneficiência Portuguesa (Niterói, RJ) e X LABS (RJ). Aceite: 13-março-1995.

Dr. Ricardo de Oliveira Souza - Rua General Belford 226 - 20961 -000 Rio de Janeiro RJ - Brasil. 
Admitindo o interesse e a deficiência de documentação que envolve a questão, apresentamos o caso de um paciente em quem determinamos os limites da lesão que ocasionou a liberação patológica da mímica de choro. Nossa atenção se ateve (i) à topografia da lesão, (ii) à caracterização do choro patológico como sintoma anátomo-clínico independente e (iii) à supressão da mímica anormal por doses baixas de imipramina. No presente estudo, "incontinência da mímica" (IM) será empregado para designar o quadro clínico de funcionamento exagerado e relativamente autônomo do aparelho neural responsável pela integração da mímica e da vocalização em expressões emocionais universais, em particular choro e riso ${ }^{8}$, considerando que essa liberação pode se acompanhar de graus variáveis de congruência da experiência emocional. Elegemos essa expressão, dentre as várias disponíveis ${ }^{1,37}$, para enfatizar o provável mecanismo em jogo, ou seja, a desconexão do sistema fácio-vocal, no tegmento do tronco cerebral, de determinados aferentes cerebrais.

\section{RELATO DO CASO}

AND, um motorista aposentado, 64 anos de idade, procurou atendimento em dezembro-1990, por causa do "derrame" que havia se instalado um mês antes. Nas semanas que o precederam, apresentou três breves episódios de duplicação visual. Na véspera, passou o dia limpando o teto de casa, mantendo a cabeça $\mathrm{em}$ extensão por várias horas. No dia do acidente, acordou às 7 horas como de hábito. Ao levantar, a esposa notou que estava falando "enrolado, que nem bêbado", mas podia andar e "fazer de tudo normalmente". Minutos depois, verificando que "sua boca estava torta", levou-o a um posto de saúde próximo, onde foi constatada pressāo arterial de "17 por 12". Medicado com Adalat ${ }^{\star}$ sublingual, precisou ser reconduzido pelo braço. Às 9 horas, não mais conseguia se manter de pé sozinho. Acompanhando os primeiros sinais deficitários, apareceram os episódios de choro incoercível, desprovidos de tristeza. Em nenhum momento vomitou, perdeu os sentidos, apresentou febre, convulsões, incontinência esfinteriana ou cefaléia. Melhorou até meados de 1993. Por ocasião da primeira consulta, havia recuperado a capacidade de ficar de pé e andar amparado. Sem história de diabetes, fumava 1 maço de cigarros por dia e bebia cerveja nos fins-de-semana desde adolescente. Em maio-1989, infarto agudo do miocárdio (parede diafragmática).

Ao exame, acordado, orientado e disártrico. Fazia-se entender pela fala e contava sua história com coerência. A avaliação cognitiva evidenciou lateralidade direita (Quociente de preferência manual $=+100$ ), preservação das funções mentais, lentificação psicomotora compatível à idade, ausência de negligência visual, bom reconhecimento de faces e má discriminação visual de formas geométricas. A metade superior da face conservava a simetria; a boca mantinha-se fechada e a comissura labial desviada diagonalmente para a esquerda, com acentuação do sulco nasolabial deste lado. Enrugamento associado do frontal nas miradas verticais superiores, acompanhamento e saques oculares presentes, convergência abolida, pupilas pequenas, isocóricas e fotorreagentes. Reflexo glabelar inesgotável, orolabial ausente, mentoniano e faríngeo presentes. Ausência do relevo subcutâneo do esternocleidomastóideo à esquerda. Sob comando, corrugava os supercílios, enrugava a fronte, arregalava e

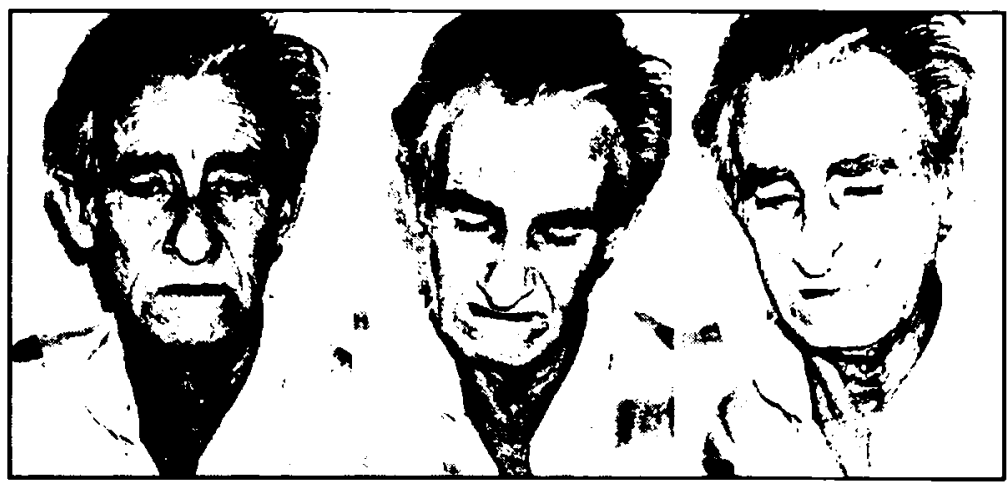

Fig I. A: Choro iminente, um mês depois do ínicio dos sintomas. B: Expressāo característica de um acesso de choro: rebaixamento da cabeça e dos traços da face. C: Solicitado a elevar a cabeça, para melhor apreciaçāo dos traços faciais. 


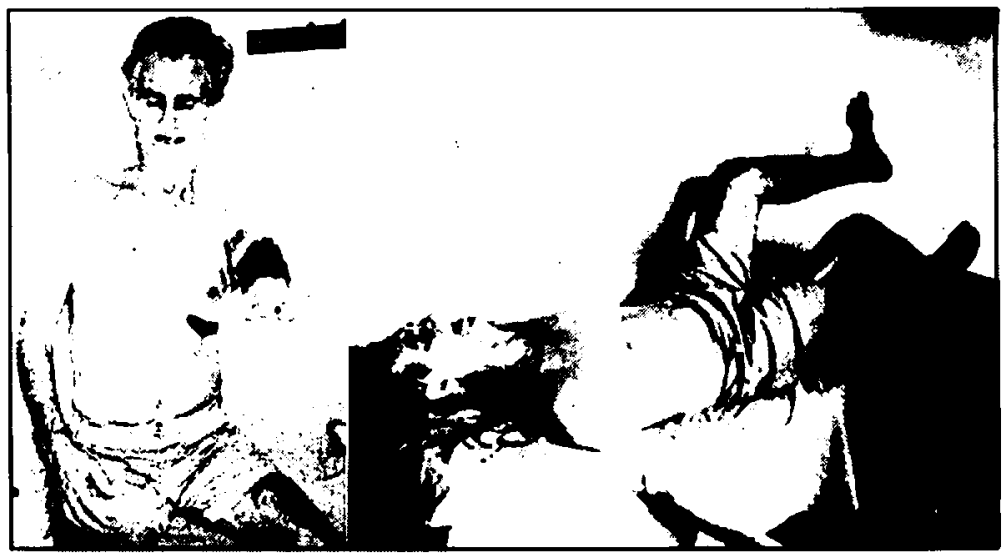

Fig 2. Situações inespecíficas de detonação do choro: manobras de Mingazzini para os membros superiores $(A)$ e inferiores $(B)$.

fechava os olhos, sem perda da simetria da face superior. A abertura forçada da boca permitia a visualizaçāo da movimentação ampla da língua e da úvula, mas não se acompanhava de contraçāo do platisma direito. Durante a fala espontânea, não se observavam movimentos associados da hemiface inferior direita e a comissura se desviava ainda mais. Hemiplegia direita, dissociação flexora-extensora. Incapaz de deambular sozinho, podia sustentar o tronco de pé e sentado. Movimentos proximais (4/5) melhor preservados que os distais (3/5). Atitude de Wernicke-Mann, espasticidade (3/3) nos flexores do MSD e extensores do MID, sinal de Babinski bilateral, inconstante à esquerda, associado à hiperreflexia flexora dos membros inferiores. Reflexos musculares hiperativos nos quatro membros, sinal de Hoffmann e clônus inesgotável do pé à direita. Hiporreflexia aferente córneopalpebral direita. Sensibilidade corporal normal a contato, vibraçāo (para frequiências em $\mathrm{C} / 128 \mathrm{~Hz}$ ), picadas de alfinete e posiçāo segmentar; grafoestesia palmar preservada. Acuidade visual normal, quadrantopsia homônima direita. Índice de Barthel $65^{39}$.

Ritmo cardíaco regular em três tempos $\left(B_{4}\right)$, sem sopros. Pressão arterial consistentemente elevada em três ocasióes diferentes, $170 \times 110 \mathrm{mmHg}$, extrassístoles ventriculares freqüentes. Ecocardiograma bidimensional: aumento do diâmetro, hipocinesia difusa e disfunção sistólica do ventrículo esquerdo; válvula mitral afastada do septo. Exames hematológicos, bioquímicos, provas funcionais renais e hepáticas e VHS normais, exceto HDL-colesterol $20 \mathrm{mg} \%$ (normal de 35 a $65 \mathrm{mg} \%$ ) e hipertrigliceridemia de $230 \mathrm{mg} \%$ (normal até $200 \mathrm{mg} \%$ ). Sorologia para lues negativa. Potenciais evocados sômato-sensitivos (membros superiores) e auditivos e reflexo de piscar normais.

Acessos de choro. Inesperados ou deflagrados por situaçôes novas ("pelo menos, até acostumar com elas"), como a entrada de alguém na sala, a manipulação de um membro ou sua própria fala. Menos comumente - mas de maneira mais previsível -, o choro era desencadeado por temas de relevância pessoal se poderia voltar a beber cerveja, ao falar da horta caseira ou da hemiplegia -, mas nāo necessariamente tristes: por exemplo, quando reproduziu a apresentação de um comediante que admira. Cada acesso de choro durava vários segundos. Não conseguindo sustá-1o, nem impedir seu aparecimento, ficava irritado, aparentemente favorecendo sua adição em sequências prolongadas. Mesmo no auge, negava sentir-se alegre ou triste "por dentro", porém nem os parentes haviam se dado conta do caráter emocionalmente vazio do choro. Apresentou vários acessos de choro nas primeiras consultas (pré-tratamento). Apesar de incongruentes, geravam frustração e aborrecimento. A Fig 3. Choro do lactente normal (6 meses de transformação da mímica costumava ser anunciada por idade).

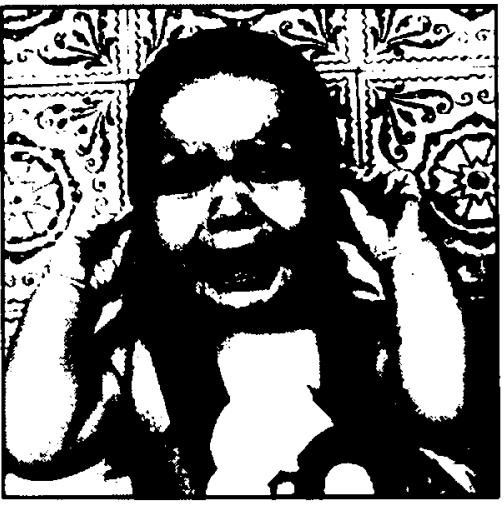


vocalização - um lamento alto, prolongado e monótono - , a partir da modificação da fisionomia de repouso, que espelhava choro iminente e pesar a maior parte do tempo (Fig 1). Os acessos típicos ocorriam sem provocação ou por estímulos inespecíficos (Fig 2). O discurso era bruscamente interrompido por vocalização, entalamentos, soluços, engasgos, lacrimejamento, congestão nasal e conjuntival, salivação, rubor facial, abalos dos ombros e modificaçāo da fisionomia, aproximando-se da expressão de choro dos recém-nascidos (Fig 3). Os supercílios

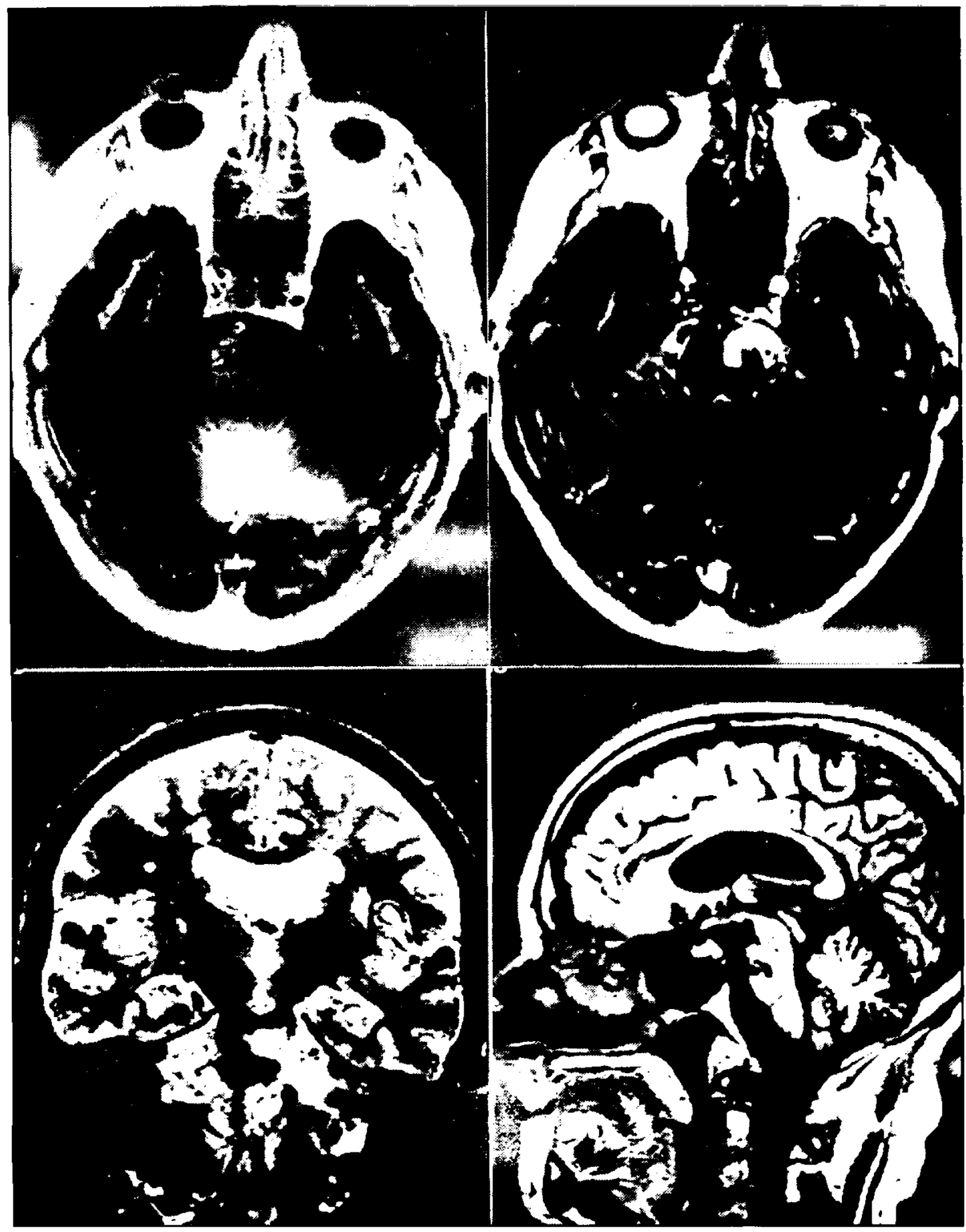

Fig 4. RNM do crânio (campo magnético $=0.5 \mathrm{~T}$ ), realizada dois anos depois da instalaçāo da hemiplegia. Em $A$, corte axial, ponderado em $T$, com recuperação inversa; em $B$, mesma orientação, ponderada em $T$, em $C$, corte coronal, onde se observa a lesão no maior comprimento lateral; em $D$, corte parasagital (5 $\mathrm{mm}$ à esquerda da linha médica), onde se identifica o aspecto cuneiforme da lesãos. 


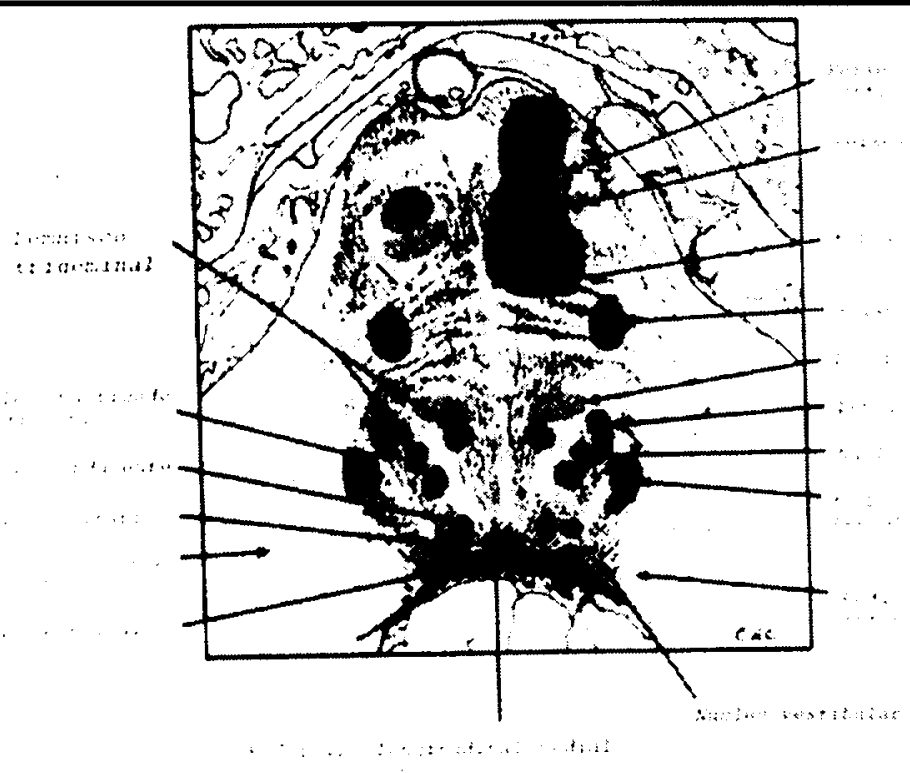

Fig 5. Esquema da lesũo, com base nos diagramas de Bradley".

se corrugavam, os olhos se rebaixavam e eram recobertos pela māo, a mandíbula se adiantava e a boca entreabria. A comissura labial, agora simétrica, se retificava e o lábio inferior se evertia, enrugando a asa do nariz e o mento. Induzido a rir, esboçava alguma expressão congruente, logo vencida pela do choro: algumas vezes, contava uma anedota e, próximo ao desfecho, irrompia em pranto; interpelado, sabia estar chorando, mas, interiormente ria-se da piada. Em nenhum momento perdeu o contato inteligível ou manifestou outros sinais de epilepsia.

Neuroimagem. Duas tomografias computadorizadas (TCs) do crânio foram obtidas após estabilização dos sintomas, mais de três meses após sua instalação. Ambas revelaram lesões hipodensas (27 uH) fixas e não captantes, em formato de cunha, no lobo occipital e na base da protuberância, à esquerda. A ressonância nuclear magnética (RNM), dois anos e meio depois do início dos sintomas, revelou áreas de sinal hipointenso em $T_{1}$, não captantes, de topografia idêntica à mostrada pela TC (Fig 4). A protuberancial tinha dimensões aproximadas de $8 \times 7 \times 7 \mathrm{~cm}$. Em T $\mathrm{T}_{2}$, pequenas áreas de sinal hiperintenso espalhadas na substância branca da região tálamoestriada e no centro oval, confluindo e realçando os contornos dos cornos frontais e occipitais dos ventrículos laterais. Na face medial do lobo occipital esquerdo, imagem cuneiforme de base cortical insinuava-se em direção ao corno posterior do ventrículo lateral, com o qual estabelecia contato. Nos terços médio e superior da divisão paramediana esquerda da protuberância, a área de contorno irregular emitia sinal hiperintenso e projetava-se para trás, interrompendo-se no tegmento e ocupando, aproximadamente, metade da seç̧ão transversa do tronco cerebral no ponto de maior extensão. $O$ formato de cunha era evidente no corte parasagital a $5 \mathrm{~cm}$ da linha média, o ápice orientado para o tegmento (Fig 5). Nas séries coronais, a artéria basilar aparecia tortuosa e dilatada, mas patente. Atrofia da pirâmide bulbar ipsilateral à lesão pontina. Em uma das reconstruçōes, uma faixa tênue de sinal hiperintenso irradiava-se para baixo a partir da lesão, tornando-se indistinta na altura do ponto correspondente à atrofia da pirâmide, indicando degeneração walleriana do feixe piramidal daquele lado ${ }^{1 \mathrm{~B}}$.

Acompanhamento. Iniciados $25 \mathrm{mg}$ de imipramina à noite, os acessos desapareceram em menos de uma semana, deixando, em seu lugar, "soluços ou engasgos" ocasionais, aos quais o paciente se referia como "tosse emocional". Não atrapalhavam o desempenho social e a fala e eram induzidos por estímulos emocionais complexos, dramáticos ou tristes. Comparava-os ao início de uma crise de choro, que, agora, "podia controlar muito melhor", Induzido a rir ou sorrir, a assimetria facial desaparecia e a fisionomia se animava por expressões naturais, notavelmente distintas dos acessos de choro (Fig 6). Ao longo do período de acompanhamento, recuperou 
a deambulação autônoma, com diminuição da hemiplegia. Persistiam a atitude espástica de Wernicke-Mann, sinal de Babinski bilateral e sinais de liberação piramidal. Apesar da deficiência de força, mais nítida nos segmentos distais dos membros, era capaz de efetuar movimentos individuais dos dedos, muito embora com lentidão e esforço, e de escrever. Índice de Barthel 90 . No mesmo período, suspendemos a medicação por duas vezes, com retorno do choro em poucos dias, desta vez desencadeado por estímulos complexos e dramáticos (meninos de rua, fome, analfabetismo), desde que "reais"; isto é, não ocorriam, por exemplo, em resposta a dramas de novelas da TV, explicitamente fictícios. A reintrodução da droga produzia retorno do controle em poucos dias (Fig 7)

\section{COMENTÁRIOS}

Esse caso ilustra algumas das alterações decorrentes do comprometimento da circulação cerebral em cardiopatas idosos: afecção difusa da substância branca dos hemisférios cerebrais e aterosclerose dos grandes vasos, mais evidente no sistema vértebro-basilar. A presença de fatores de risco, o formato e a localização da imagem occipital sugeriu embolia da artéria cerebral posterior. A hemiplegia motora pura protuberancial se ajustou ao mecanismo de oclusão, na origem, de um ramo paramediano da basilar ("doença ateromatosa de ramo intracraniano") ${ }^{15}$. Nighoghossian e col..$^{42}$ verificaram que as hemiplegias protuberanciais constituem $100 \%$ das "hemiplegias CT-negativas", representam $30 \%$ das hemiplegias como um todo e implicam em pior prognóstico. Resultam, mais comumente, de infartos dos terços médio e caudal da base da protuberância, território paramediano da artéria basilar' ${ }^{\top}$ O paciente que relatamos foge a muitas dessas prediçōes: a lesão pontina manifestouse à TC e seu prognóstico não foi pior do que o da maioria das hemiplegias capsulares.

A incontinência do choro constituiu o aspecto mais notável deste caso. $O$ choro e o riso patológicos são definidos: (i) pela ausência de controle voluntário sobre intensidade e duração das crises ("sequência automática"); (ii) pelo caráter espontâneo (nāo induzido), estímulo-inespecífico ou exagerado; e (iii) por serem emocionalmente "vazios" ou incongruentes, isto $e$, dissociados da experiência emocional ${ }^{37,43}$. Na maioria dos casos, a necrópsia revela lesões espalhadas pela profundidade dos hemisférios cerebrais, o que dificulta correlações anátomo-clínicas sistemáticas ${ }^{44}$. Menos comumente, restringem-se à região lentículo-capsular anterior ${ }^{13,14,17,20}$ ou à base da protuberância. Esta topografia, relativamente negligenciada até há pouco tempo, foi revivida nas publicações de Tatemichi e col. ${ }^{49}$, Yarnell ${ }^{54}$ e de Andersen e col. ${ }^{4}$, que recolheram respectivamente, 5,4 e 4 casos de choro patológico por lesões pontinas.

Incontinência da mininica e desconexão límbico-motora. A IM inspirou a identificação dos mecanismos da expressão emocional, denominados "sistema fácio-respiratório" por Wilson" ${ }^{53}$, em

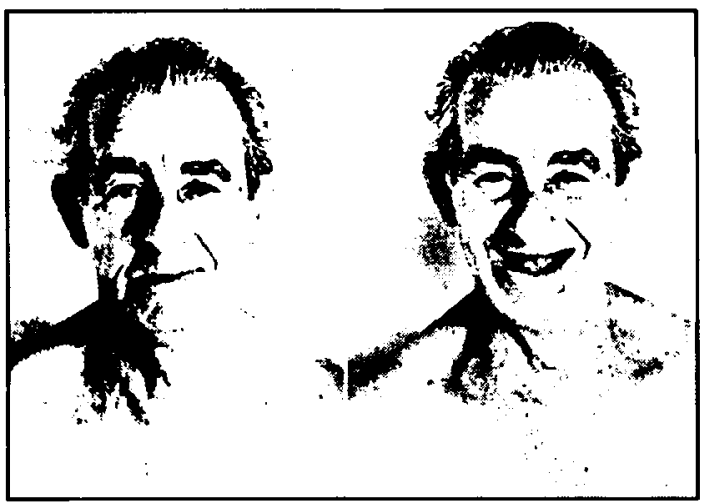

Fig 6. A: em tratamento; face em repouso assimétrica (desvio da comissura labial para a esquerda). B: desaparecimento da assimetria no riso natural. reconhecimento da estreita ligação entre mímica e vocalização na expressão das emoções inatas. $O$ aparelho neural básico, organizado no tegmento do tronco cerebral, é modulado por aferentes (descendentes) cerebrais, do próprio tronco cerebral e medulares (ascendentes) ${ }^{26}$. A lesão seletiva de seus componentes, no tegmento, produz o quadro inverso de paralisia da expressão emocional ("amimia") com preservação dos movimentos voluntários da face ${ }^{33}$. Nas pessoas normais, $o$ aparelho fácio-vocal opera como efetor das estruturas do "cérebro límbico" que processam a experiência emocional ${ }^{22}$. Sugerimos, como primeira aproximação, que, no nosso paciente, o aparelho da mímica estava 


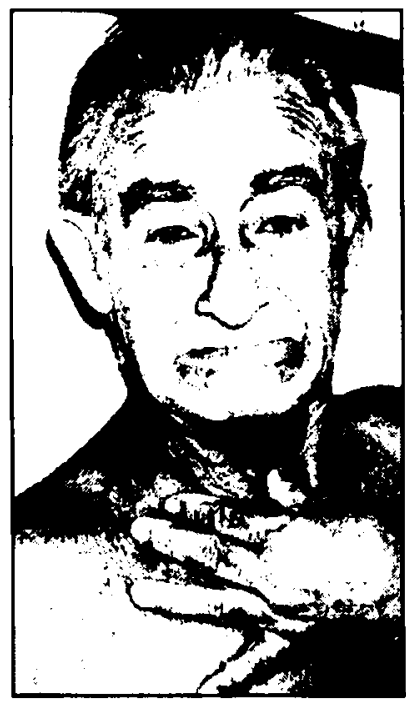

Fig 7. Reaparecimento da incontinência do choro após suspensāo da imipramina. intacto e funcionando independente da regulação emocional organizada rostralmente. A dissociação entre expressão (choro incontido) e experiência emocional foi a consequência mais evidente do fenômeno. A lesão parece ter atingido algumas das conexōes descendentes do circuito fácio-respiratório no tegmento (feixe tegmental central? feixe tegmental medial? ${ }^{51}$ ), cedendo lugar à desinibição isolada do choro e configurando uma verdadeira desconexão límbico-motora. A ausência de desinibição concomitante do riso neste caso e a desinibição isolada do riso em casos da literatura ${ }^{3,6,17,23,46,52}$, indica que a interrupção foi parcial e enfatiza a natureza seletiva do controle cerebral sobre a expressão emocional.

A consciência de retomada de controle, concomitante à redução do choro anormal, sugeriu que a recuperação tenha transcorrido por etapas, o sintoma tornando-se controlável e congruente - ocorrendo, por exemplo, somente em resposta a dramas da vida real - antes de desaparecer. O retorno do controle não parece ter-se devido, simplesmente, à recuperação motora, uma vez que, até o início do tratamento, os episódios de choro persistiam, a despeito da regressão da hemiplegia, como indicado pela elevação do indice de Barthel. Tampouco a resposta à imipramina pareceu depender de qualquer intermediação antidepressiva, em primeiro lugar, pelo simples fato de que o paciente não estava deprimido e, em segundo, por que os tricíclicos são igualmente eficazes em casos de incontinência do riso ${ }^{46}$. Por outro lado, é interessante relembar a estreita relação que se estabeleceu entre o controle/reaparecimento do choro, a introdução/suspensão da droga e as propriedades farmacocinéticas, em especial a meia-vida longa, da imipramina ${ }^{45}$. Assim, é provável que tenha-se processado um efeito específico do tricíclico sobre a liberação anômala da mímica $^{33}$. A eficácia e a seletividade de outras drogas - fluoxetina ${ }^{24,48}$, levodopa ${ }^{50}$, amitriptilina ${ }^{16,47}$, doxepina ${ }^{47}$, salicilato de bismuto ${ }^{31}$, citalopram $^{5}$-, que atuaram com sucesso em casos individuais, aguarda confirmação de mais estudos sistemáticos.

Incontinência da mímica, sindrome pseudobulbar e localizações cerebrais. Nosso paciente apresentou IM na ausência de síndrome pseudobulbar ( $\mathrm{Spb}$ ): apenas a incontinência do choro e o resíduo da hemiplegia protuberancial venceram a fase aguda da lesão. A disartria logo retrocedeu, a mobilidade do pálato e da língua era ampla e a deglutição normal. Da tétrade pseudobulbar clássica ${ }^{19}$ - disartria, disfagia, prosopoparesia inferior e disfonia - , apenas a paresia facial inferior foi consistente, testemunhando o acometimento resrtrito de fascículos córtico-faciais ${ }^{27,28,30}$. Além disso, não apresentou qualquer dos acompanhantes comuns da Spb, como demência, depressão, paraparesia espástica e incontinência esfinteriana. Essas constatações tornam mais uma vez evidente a independência sindrômica e anátomo-funcional entre a IM e da Spb. O valor de localização da-IM dependerá, em última análise, da confirmação ou da refutação desse postulado.

Apenas anos depois dos textos que definiram a $\mathrm{Spb}^{34,38}$, Lépine $^{35}$, Bechterew e Brissaud $^{13}$ publicaram os primeiros casos de incontinência de choro por lesão cerebral focal. Dejerine ${ }^{19}$, por outro lado, dedicou-se à paralisia pseudobulbar sem mencionar a IM. Em outras palavras, nenhum deles tratou a Spb e a IM como síndrome única, tendência que parece ter-se consolidado apenas em períodos posteriores ao reconhecimento de ambas. Sob esse aspecto, é possível que uma das causas do engano se deveu à influência crescente da noção de "focos de desintegração lacunar"40 como substrato anátomo-patológico comum às duas síndromes. Todavia, quaisquer que tenham sido as razões, na década de 30 Langworthy e Hesser $^{32}$ discutiam a "liberação emocional" como manifestação genuína dos casos "típicos" da Spb, cuidando em distingüi-la dos "fenômenos acessórios" (allied phenomena). Tal concepção se manteve estável ao longo dos anos subseqüentes². 
A confusão entre IM e Spb persiste na literatura moderna. Por exemplo, Tatemichi e col. ${ }^{49}$ se $^{2}$ referiram à incontinência do choro como "síndrome pseudobulbar pontina". Mouton e col. ${ }^{41}$ iniciaram artigo afirmando que "o riso e choro espasmódico é sintoma caracterísitco da síndrome pseudobulbar". Ironicamente, sua paciente não preenchia os critérios clássicos da Spb, pois não apresentava disfagia. Não obstante, o peso da evidência anátomo-clínica contemporânea favorece a independência sindrômico-topográfica da IM. Asfora e col. ${ }^{6}$, por exemplo, relataram um paciente com episódios frequentes e incapacitantes de riso e choro por ruptura de uma mal formação vascular paramediana na base da protuberância, sem outros sinais neurológicos. Besson e col. ${ }^{y}$ encontraram choro e riso patológicos em somente um dos 13 pacientes com $\mathrm{Spb}$. Na série de 8 pacientes com mutismo agudo por lesões bicapsulares posteriores, Helgason e col..$^{25}$ verificaram a ocorrência de "afeto pseudobulbar" em quatro. Nenhum dos 6 pacientes de Bogousslavsky e Regli ${ }^{10}$, que desenvolveram Spb contralateral à lesōes genucapsulares vasculares unilaterais, apresentou IM. Leys e col..$^{36}$ assinalaram a ausência de choro e riso patológico em uma paciente com $\mathrm{Spb}$ por lesões supracapsulares simétricas. Nenhum dos 21 pacientes de Nighoghossian e col. ${ }^{42}$ com hemiparesia motora pura (capsular em $15 \mathrm{e}$ ventroprotuberancial em 6) apresentou IM. Andersen e col.4 estudaram 12 pacientes com choro patológico por lesões vasculares de topografia e volume variados: 4 pontinas, 7 hemisféricas e 1 cerebelar + atrofia cortical. A gravidade do choro se correlacionou com a extensão das lesões protuberanciais, em particular com o grau de acometimento dos núcleos (serotoninérgicos) da rafe. Esses e outros casos ${ }^{13.20,21,29}$ não deixam dúvidas de que não é necessário, nem suficiente, que os feixes córtico-nucleares sejam lesados para que ocorra IM.

Se, hoje, a maioria dos estudos anátomo-clínicos concorda que as lesōes que produzem a Spb se aloja nos fascículos córtico-bulbares, o mesmo não acontece para as estruturas cuja lesão se exterioriza por IM, como se pode depreender, por exemplo, das revisões de Poeck ${ }^{43,44}$. De modo geral, todavia, a literatura clínico-anatômica disponível nos convida a algumas conclusōes: sob o aspecto negativo, lesões isoladas do neocórtex ou dos feixes córtico-nucleares não bastam para promover a desinibição patológica da mímica. Aparentemente, em todos os casos em que isto pareceu ocorrer, estruturas vizinhas, nem sempre devidamente valorizadas pelos diferentes observadores, foram envolvidas pela lesão principal. De positivo, as regiões que mais facilmente dão origem à IM estão agrupadas cm duas áreas: na regiāo lentículo-capsular anterior e no tegmento protuberancial, rostral ao núcleo do nervo facial.

Esse mapeamento, ainda que provisório, sugere a hipótese de trabalho de que a IM, ao menos em boa parte dos casos, resulta da destruição de territórios cerebrais dependentes de setores arteriais definidos: dos ramos lentículo-estriados mediais (artéria cerebral anterior) e dos ramos paramedianos da basilar. Interessante, esses vasos parecem deter uma suscetibilidade particular à oclusāo aterosclerótica em sua origem ${ }^{15}$. Seguramente, a identificação mais acurada das bases neurais da mímica no homem dependerá, criticamente, do deslocamento da atenção do observador da base do tronco (feixes córtico-nucleares) para o tegmento.

Agradecimento - Agradecemos aos Drs. Dayse Lucia Gusmão pelas críticas ao manuscrito, Andreas Manger, pelo texto de Magnus (Referência 38) e Mauricio Klajnberg, pelos exames eletrofisiológicos; à Prof. Marlene Soares Dos Santos pela revisão do resumo em inglês e aos funcionários das bibliotecas do Instituto Oswaldo Cruz (IOC-MS) e do Centro de Ciências da Saúde da Universidade Federal do Rio de Janeiro (CCSUFRJ), pela eficiência na obtenção dos textos originais.

O paciente autorizou a publicação das fotografias.

\section{REFERÊNCIAS}

1. Allman P. Crying and laughter after brain damage: a confused nomenclature. J Neurol Neurosurg Psychiatry, 1989, 52: 1439-1440.

2. Aring CD. Supranuclear (pseudobulbar) palsy. Arch Intern Med. 1965, 115: 198-199.

3. Andersen C. Crise de rire spasmodique avant décès: hémorthagie thalamique double. J Belge Neurol Psychiat, $1936,36: 223-227$ 
4. Andersen G, Ingeman-Nielsen M, Vestergaard K, Riis JO. Pathoanatomic correlation between poststroke pathological crying and damage to brain areas involved in serotoninergic neurotransmission. Stroke 1994, 25: $1050-1052$.

5. Andersen G, Vestergaard K, Riis JO. Post-stroke pathological crying treated with the selective serotonin reuptake inhibitor, citalopram Lancet. 1993, 342: 837-839.

6. Asfora WT, DeSalles AA, Abe M, Kjellberg RN. Is the syndrome of pathological laughing and crying a manifestation of pseudobulbar palsy ? J Neurol Neurosurg Psychiatry 1989, 52: 523-525.

7. Bassetti C, Bogousslavsky J, Barth A, Regli F. Paramedian pontine infarct: clinical- topographic correlation. Neurology 1993, 43: A159.

8. Bechterew W. Unaufhaltsames Lachen und Weinen bei Hirnaffectionen. Arch Psychiat Nervkrank 1894, 26: 791-817.

9. Besson G, Bogousslavsky J, Regli F, Maeder P. Acute pseudobulbar or suprabulbar palsy. Arch Neurol 1991, 48: 501-507.

10. Bogousslavsky J, Regli F. Capsular genu syndrome. Neurology 1990, 40: 1499-1502.

11. Bradley WG. MR of the brain stem: a practical approach. Radiology 1991, 179: 319-332.

12. Brissaud E. Sur le rire et le pleurer spasmodiques. In: Leçons sur le Maladies Nerveuses. Paris: G Masson, 1895, p 446-448.

13. Brissaud E. Rire et pleurer spasmodiques. Rev Neurol (Paris) 1900, 9:824-825.

14. Burzio F. Emiplegia con dolori ed accessi di riso spasmodico do rammollimento di nucleo lenticulare interessanti la capsula interna. Ann Freniatr Sci Affini 1900, 10: 140-148.

15. Caplan LR. Intracranial branch atheromatous disease: a neglected, understudied, and underused concept. Neurology 1989, 39: 1246-1250.

16. Caroscio JT, Cohen JA, Gudesblatt M. Amitriptyline in amyotrophic lateral sclerosis. N Engl J Med 1985 , 313: 1478-1479.

17. Ceccaldi M, Poncet M, Milandre L, Rouyer C. Temporary forced laughter after unilateral strokes. Eur Neurol 1994, 34: 36-39.

18. Danek A, Bauer $M$, Fries $W$. Tracing of neural connections in the human brain by magnetic resonance imaging in vivo. Eur J Neurosci 1990, 2: 112-115.

19. Dejerine J. La paralysie pseudo-bulbaire. Journal des Practiciens 1914, 21: 406-408.

20. Dupré E, Devaux A. Rire et pleurer spasmodiques par ramollissement nucléo-capsulaire antérieur: syndrome pseudo-bulbaire par désintégration lacunaire bilatérale des putamens. Rev Neurol (Paris) 1901, 9: 919-926.

21. Féré C. Paralysie pseudo-bulbaire par lésion cérébrale bilatérale. Rev Méd (Paris) 1882, 11: 858-861.

22. Gloor P, Olivier A, Quesney LF, Andermann F, Horowitz $S$. The role of the limbic system in experiential phenomena of temporal lobe epilepsy. Ann Neurol 1982, 12: 129-144.

23. Geschwend J. Dissoziiertes Lachen und Weinen bei apoplektischen Insult. Fortschr Neurol Psychiat 1978, 46: 29-32.

24. Hanger HC. Emotionalism after stroke. Lancet 1993, 342: 1235-1236.

25. Helgason C, Wilbur A, Weiss A, Redmond KJ, Kingsbury NA. Acute pseudobulbar mutism due to discrete bilateral capsular infarction in the territory of the anterior choroidal artery. Brain 1988, 111: 507-524.

26. Holstege $G$. Descending motor pathways and the spinal motor system: limbic and non-limbic components. Progr Brain Res 1991, 87: 307-421.

27. Hopf HC, Tettenborn B, Krämer G. Pontine supranuclear facial palsy. Stroke 1990, 21: 1754-1757.

28. Huang CA, Broe G. Isolated facial palsy: a new lacunar syndrome. J Neurol Neurosurg Psychiatry 1984, 47: 84-86.

29. Ironside R. Disorders of laughter due to brain lesions. Brain 1956, 79: 589-609.

30. Iwatsubo T, Kusuhara S, Kanemitsu A, Shimada H, Toyokura Y. Corticofugal projections to the motor nuclei of the brainstem and spinal cord in humans. Neurology 1990, 40: 309-312.

31. Kamosh LJ, Connor WH. Syphilitic pseudobulbar palsy with compulsive weeping. Am J Syph Gon Ven Dis 1936, 20: 115-123.

32. Langworthy OR, Hesser FH. Syndrome of pseudobulbar palsy: an anatomic and physiologic analysis. Arch Intern Med 1940, 65: 106-121.

33. Lawson IR, MacLeod RDM. The use of imipramine (Tofranil ${ }^{\varpi}$ ) and other drugs in organic emotionalism. Br J Psychiatry 1969, 115: 281-285.

34. Lépine R. Note sur la paralysie glosso-labiée cérébrale a forme pseudo-bulbaire. Rev Mens Med Chir 1877, 1: $909-922$.

35. Lépinc R. Paralysie glosso-labiée cérébrale: rire et pleurer spasmodiques. Rev Méd (Paris) 1896, 16: 263-270.

36. Leys D, Lejeune JP, Bourgeois P, Blond S, Petit H. Syndrome pseudo-bulbaire aigu: infarctus bilatéral de la jonction capsule interne-corona radiata. Rev Neurol (Paris) 1985, 141: 814-818. 
37. Lieberman A, Benson F. Control of emotional expression in pseudobulbar palsy. Arch Neurol 1977, 34: 717-719.

38. Magnus A. Fall von Aufhebung des Willenseinflusses auf einige Himnerven. Müller's Arch 1837, 258-266.

39. Mahoney FL, Barthel DW. Functional evaluation: the Barthel index. Md State Med J I965, 14: $61-65$.

40. Marie P. Des foyers de désintégration et de différents autres états cavitaires du cerveau. Rev Méd (Paris) 1901, 21: 281-298.

41. Mouton P, Rémy A, Cambon H. Rire spasmodique par lésion unilatérale du tronc cérébral. Rev Neurol (Paris) 1994, 150: 302-303.

42. Nighoghossian N, Ryvlin P, Trouillas P, Laharotte JC, Froment JC. Pontine versus capsular pure motor hemiparesis. Neurology 1993, 43: 2197-2201.

43. Poeck K. Pathological laughter and crying. In Vinken CI, Bruyn GW (eds). Handbook of Clinical Neurology, Vol 1 (45): Clinical Neuropsychology, Frederiks JAM, ed. Amsterdam: Elsevier B.V. 1985, p 219-225.

44. Poeck K, Pilleri G. Pathologisches Lachen und Weinen. Arch Neurol Psychiatr 1964, 92: 323-370.

45. Preskhorn SH. Pharmacokinetics of antidepressants: why and how they are relevant to treatment. J Clin Psychiatry 1993, 54 (Suppl 9): 14-34.

46. Ross ED, Rush AJ. Diagnosis and neuroanatomical correlates of depression in brain-damaged patients. Arch Gen Psychiatry 1981, 38: 1344-1354.

47. Schiffer RB, Cash J, Herndon RM. Treatment of emotional lability with low-dose tricyclic antidepressants. Psychosomatics 1983, 24: 1094-1096.

48. Sloan RL, Brown KW, Pentland B. Fluoxetine as a trentment for emotional lability after brain injury. Brain Inj 1992;6: 315-319.

49. Tatemichi TK, Nichols FT, Mohr JP. Pathological crying: a pontine pseudobulbar syndrome. Ann Neurol $1987 ; 22: 133$.

50. Udaka F, Yamao S, Nagata H, Nakamura S, Kameyama M. Pathologic laughing and crying treated with levodopa. Arch Neurol 1984, 41: 1095-1096.

51. Voogd J, Fcirabend HKP, Schoen JHR. Cerebellum and precerebellar nuclei. In Paxinos G (ed). The Human Nervous System. San Diego: Academic Press, 1990, p 321-386.

52. Wali GM. "Fou rire prodromique" heralding a brainstem stroke. J Neurol Neurosurg Psychiatry 1993, 56: 209-210.

53. Wilson SAK. Some problems in neurology: II. Pathological laughing and crying. J Neurol Psychopathol 1924, 16: 299-333.

54. Yarnell PR. Pathological crying localization. Ann Neurol 1987, 22: 133-134. 